\title{
INSTITUCIONALIZAÇÃO DE SISTEMAS MUNICIPAIS DE EDUCAÇÃO: CONCEPÇÕES E COMPLEXIDADE
}

Resumo: Este trabalho discute concepções e aspectos da complexidade histórica quanto à gestão da educação municipal brasileira, abordando o processo de institucionalização efetiva de sistemas municipais de educação. Com base em pesquisa bibliográfica e análise documental, são destacadas condições e desafios, fragilidades e potencialidades que permeiam a existência dos municípios e sua atuação na educação. Sua relevância está, então, em discutir processos, políticas e ações para que essas esferas participem do processo da garantia do direito à educação. Nesse contexto, a institucionalização de sistemas municipais passa a ser questão relacionada ao pacto federativo e ao regime de colaboração, extrapolando a política ou programas de municipalização, visando firmar a autonomia na gestão.

Palavras-chave: Sistemas de educação. Institucionalização efetiva de Sistemas Municipais de Educação. Política educacional. Gestão da educação. Educação municipal.

\section{Institutionalization of municipal education systems: concepts and complexity}

\begin{abstract}
This paper discusses concepts and aspects of historical complexity regarding the management of Brazilian municipal education, focusing on the process of effective institutionalization of municipal education systems. Based on a literature review and document analysis, conditions and challenges, and potentialilies and weaknesses that permeate the existence of municipalities and their role in education are highlighted. Its relevance is, then, to discuss processes, policies and actions for these

\footnotetext{
* Doutora e Mestre em educação pela Universidade Federal de Goiás; Professora do Curso de Pedagogia da Universidade Federal de Tocantins, Campus de Palmas; Professora do Programa de Mestrado em Educação da Universidade Federal de Tocantins; Avenida NS 15, 109, Norte - Plano Diretor Norte, 77001090, Palmas, Tocantins, Brasil; roselagares@uft.edu.br
} 
spheres participate in the process of ensuring the right to education. In this context, the institutionalization of municipal systems becomes a question related to the federal agreement and collaboration system by extrapolating policy or municipalization programs aiming to establish autonomy in management.

Keywords: Education systems. Effective institutionalization of Municipal Education Systems. Educational policy. Management education. Municipal education.

\section{INTRODUÇÃO}

Este trabalho teve como objetivo abordar concepções e aspectos da complexidade quanto à gestão da educação municipal, em especial, na opção de organização por meio de processo de institucionalização efetiva de Sistemas Municipais de Educação (SME).

A relevância desta pesquisa sustenta-se pela discussão, em si, das responsabilidades jurídicas, políticas e administrativas, para que os municípios participem efetivamente na constituição do Sistema Nacional de Educação e, especialmente, cumpram suas atribuições na garantia do direito à educação para todas as pessoas indistintamente.

O corpus teórico deste trabalho foi construído com base em pesquisa bibliográfica, abordando um conjunto de produções científicas consideradas salutares, de intelectuais renomados que vêm se dedicando ao estudo dos novos desenhos no campo das políticas públicas, da legislação e da gestão da educação, a partir dos anos 1990, sobretudo no âmbito dos municípios, o que significou “[...] realizar um movimento incansável de apreensão dos objetivos, de observância das etapas, de leitura, de questionamentos e de interlocução crítica com o material bibliográfico, e que isso exige vigilância epistemológica.” (LIMA; MIOTO, 2007, p. 37).

As fontes documentais foram, especificamente, espécies normativas da educação brasileira, como a Constituição Federal, emendas constitucionais, leis e atos normativos do Conselho Nacional de Educação (CNE), materiais que vêm recebendo vários tratamentos analíticos por outros pesquisadores, mas que, neste caso, receberam outras interpretações.

A análise documental, compreendida como um procedimento que se utiliza de métodos e técnicas para a apreensão, compreensão e análise de documentos dos mais variados tipos (ALMEIDA; GUINDANI; SÁ-SILVA, 2009), favoreceu a observação de concepções e conceitos (CELLARD, 2008). 
No Brasil, é complexa a discussão quanto à concepção de sistema no âmbito da educação nacional, que desde os anos 1970 se acirra e se torna mais fundamentada teoricamente, envolvendo tanto a sua história e natureza quanto aspectos como nomenclatura, características, elementos constitutivos, objetivos e finalidades.

Cury (2000), no Parecer do Conselho Nacional de Educação da Câmara de Educação Básica (CNE/CEB) n. 30/2000 (BRASIL, 2000), comenta a opção brasileira pela organização educacional de forma plurissistêmica, e não por um Sistema Nacional de Educação, explicitando ser tema polêmico e complexo. No sistema plural, há a descentralização e a unificação. De um lado, os sistemas de ensino federal, do Distrito Federal, estaduais e municipais, correspondendo às esferas do poder público, são autônomos entre si e responsáveis por campos específicos de atuação. De outro, a unificação deve ser garantida por meio dos princípios, fins, obrigações e articulação cooperativa dos entes federativos entre si e sob a coordenação da União. A perspectiva é, então, de uma organização da educação nacional em que estejam presentes articulação, coordenação, ausência de antinomia e unidade nos fins. A articulação é garantida com normas e finalidades gerais, por meio de competências privativas, concorrentes e comuns, e é desta concepção articulada que decorre a exigência de um Plano Nacional de Educação (PNE).

Segundo o Parecer CNE/CEB n. 34/2001 (BRASIL, 2001b), a Legislação busca estabelecer não apenas um Sistema Nacional de Educação, mas um sistema plural e descentralizado.

Saviani (1996) argumenta que, no Brasil, foi postergada a questão da constituição do sistema de educação, e que ainda não existe um sistema organizado em âmbito nacional. Em decorrência disso, o déficit foi se acumulando e neutralizando os esforços parciais que se fizeram ao longo dos últimos cem anos.

Gadotti (2000), por sua vez, afirma que no Brasil não existe propriamente um Sistema Nacional de Educação, pois os vários subsistemas funcionam, frequentemente, como estruturas justapostas, sem articulação, considerando-se que um sistema nacional pressupõe a articulação, e não a justaposição, nem a anulação de um sistema por outro.

Embora a referência ao Sistema Nacional de Educação seja usual na literatura educacional e até em documentos oficiais, apenas em 2009, com a Emenda Constitucional (EC) n. 59, art. 214 (BRASIL, 2009), é que o país passa a conviver normativamente com a disposição desse sistema.

Como se lê inicialmente, nesse movimento de interlocução crítica com o material bibliográfico e nas interpretações documentais foi possível apreender um 
cenário complexo e de concepções em disputa no que diz repeito à definição do que seja um sistema de educação. Contexto em que se encontra a esfera municipal, com outras responsabilidades na gestão da educação, devendo ocupar outros espaços nesse novo desenho institucional.

Assim posto, a despeito de teses de democratização da descentralização das políticas educacionais, o campo municipal ainda se confronta com dificuldades que se acumulam de natureza histórica, política, econômica e cultural. Há abrangências a serem compreendidas, analisadas e avaliadas no contexto de cada localidade. Desta feita, entre outras, algumas temáticas carecem de investigação, como as opções legais de organização da educação municipal à luz de suas condições, possibilidades e intencionalidades.

\section{ORGANIZAÇÃO E GESTÃO DOS SISTEMAS MUNICIPAIS DE EDUCAÇÃO: ASPECTOS DA COMPLEXIDADE HISTÓRICA}

Educadores integrantes do Fórum em Defesa da Escola Pública (1987) são contrários à ideia de atribuir exclusivamente aos municípios a responsabilidade pelo ensino básico, com a justificativa de que, sendo os municípios heterogêneos em termos de recursos, a municipalização ampliaria a defasagem entre eles. Nesse sentido, a proposta mais aceita é a de que o município atue prioritariamente, mas não exclusivamente na educação infantil e no ensino fundamental. E que a União e os estados assumam um papel compensatório, atendendo a locais com dificuldades (DUARTE, 2003).

Nos anos 1990, em cenário político pautado pelas orientações neoliberais, acentuam-se as proposições relativas à redução da ação do estado. No que diz respeito à educação, segmentos mais à esquerda, que defenderam, anteriormente, a restrição da autonomia dos sistemas municipais, passaram a apoiar sua autonomia política, em razão da incapacidade fiscal de governos estaduais e municipais. Assim, manifestam diferentes posicionamentos quanto à autonomia dos SME, com propostas de maior ou menor intervenção da União na oferta de educação básica (DUARTE, 2003).

Sander (1993) alerta que o município deve conquistar a capacidade de organizar seu sistema de educação, não sendo, portanto, compulsório. Para essa conquista, precisam ser estabelecidas condições que implicam uma definição certa dos encargos a serem atribuídos a cada um dos níveis de governo e uma radical reforma tributária, para possibilitar aos municípios condições de autossustentação. Nas palavras de Sander (1993, p. 357), sem essas condições “[ [...] em vez de promover sistemas 
municipais de ensino, a sociedade brasileira correrá o risco histórico de criar sistemas abandonados de ensino nos numerosos Municípios do interior do país."

Fonseca (1995) argumenta que não se pode ignorar o município, e, também, a municipalização não pode ser uma medida isolada. É necessário que se faça um diagnóstico da situação da educação no município e somente se implante a municipalização em bases realistas e sólidas. A municipalização poderá ser implantada, ou não, dependendo de informações e consultas à população, sob pena de se transformar em prefeiturização ou municipalização por decreto. A prudência recomenda que se comece por municipalizar a preocupação com o problema educacional.

Em meio a essas discussões e teses chamando atenção para as fragilidades das esferas municipais, em 1996 ocorre uma síntese jurídica, com o reconhecimento legal da autonomia dos SME, em consequência, sobretudo da LDB (BRASIL, 1996b), da EC n. 14 (BRASIL, 1996c) e da Lei n. 9.424 (BRASIL, 1996a) (DUARTE, 2003).

Ao mesmo tempo, acirram-se disputas no campo teórico-político e as propostas da gestão da educação nacional, no período de 1995 a 2002, provocam análises e discussões, prosseguindo com o dissenso relativo à atuação dos municípios no campo da educação.

Souza e Carvalho (1999) afirmam ser indiscutível que a descentralização político-administrativa e financeira, associada à redemocratização e às disposições da CF (BRASIL, 1988), aumenta a autonomia das instâncias subnacionais de poder, favorece a ampliação dos espaços de participação e a emergência de experiências alternativas e inovadoras em programas sociais e nas próprias concepções e modelos de gestão. A despeito de todos os constrangimentos financeiros, os municípios também estão ampliando suas ações e responsabilidades na área social. Contudo, a maior parte dessas iniciativas acontece nas áreas mais desenvolvidas do país. Assim, a descentralização das políticas sociais avança de forma diferenciada e descontínua, com características e feitos bastante heterogêneos.

Por outro lado, o governo federal tem modificado o sistema brasileiro de políticas sociais, deixando sob a responsabilidade dos estados e municípios boa parte das ações na área da habitação, saúde, saneamento básico, educação e assistência social. A heterogeneidade inter e intrarregional do país e o nível de desigualdades existentes, a descentralização fiscal e as novas disposições da CF (BRASIL, 1988), associadas à retração do governo federal, não asseguram que estados e municípios ampliem de modo espontâneo e eficiente suas responsabilidades sociais.

A heterogeneidade existente torna, muitas vezes, problemática a capacidade de atuação da esfera local, a quem a reforma do Estado atribui um papel privi- 
legiado. A parcela de municípios que dispõe efetivamente de condições financeiras, institucionais, políticas e técnico-administrativas para assumir esse papel, inovando, ampliando a eficácia, a participação e a democratização das políticas públicas, é relativamente pequena. Na maioria dos casos, e notadamente nas regiões e áreas menos desenvolvidas, predominam municípios de reduzido porte, cujas economias de base agrícola são pouco diversificadas, estagnadas ou em crise e, por isso mesmo, são desprovidas de condições mínimas de sustentação e necessitando da solidariedade dos governos do estado e federal (SOUZA; CARVALHO, 1999).

Em um país de vasta dimensão territorial, marcado por profundas desigualdades inter e intrarregionais, os efeitos da descentralização e das reformas tendem a variar substancialmente, podendo, por exemplo, aumentar a própria desigualdade de condições de acesso e permanência e/ou da oferta de uma escola com um padrão de qualidade. Portanto, a valorização da instância local não pode assumir um caráter absoluto nem a descentralização ser efetuada sem se considerar a complexa combinação de fatores (econômicos, demográficos, sociais e políticos) que, em cada contexto, define as possibilidades de transformação do setor público (SOUZA; CARVALHO, 1999).

Carências de ordem financeira estão comumente associadas àquelas de capacitação técnico-administrativas, acentuadas, mais recentemente, com a desativação ou redução do apoio institucional da União e dos estados aos governos locais. Nessas condições, atribuir simplesmente a esses governos a responsabilidade por políticas e serviços básicos pode levar à sua ausência ou até a distorções (SOUZA; CARVALHO, 1999).

Souza e Carvalho (1999) apontam, ainda, uma premissa da descentralização pouco enfatizada na literatura publicada no Brasil: a da liberdade das instâncias, setores ou grupos para decidirem o que fazer com os recursos e o poder que lhes forem transferidos. A descentralização permite que as prioridades locais sejam decididas sem a participação do centro. Assim, em um país tão heterogêneo, esperar que esse processo induza automaticamente à uniformização e à universalização do acesso da população a todos os serviços sociais que são transferidos para as esferas subnacionais não apenas parece irreal como contradiz as próprias premissas que integram o conceito de descentralização.

Amaral (1994, p. 3 apud ABREU, 1999, p. 31-32) argumenta que uma análise dos Planos Decenais de Educação, elaborados pelos municípios, em 1994, aponta uma cultura da dependência. Esse modelo de relações centralizadas (MEC/estado/ municípios) levou os municípios a uma atitude de expectativa em relação aos recursos e orientações do MEC e dos estados, sem espaço e vontade para trilhar caminhos 
próprios. Criou-se, então, uma dependência que, com o passar do tempo, cristalizou-se em uma cultura, ao firmar-se como um padrão de comportamento organizacional.

Abreu (1999) entende, também, que a existência de competências concorrentes ou comuns entre os entes federados tem gerado tensão, resultando, muitas vezes, em sobreposição ou omissão do poder público, em questões fundamentais para a sociedade. Como sobreposição, é possível destacar a distribuição não proporcional da oferta do ensino fundamental pelas esferas estadual e municipal com instituições muito próximas geograficamente. Já como omissão, apresenta-se a atuação de municípios com a oferta de um número de matrícula inferior à sua capacidade de atendimento ou, até mesmo, o Estado ausentar-se totalmente de responsabilidades com esse nível de educação, no conjunto de seu território, tomando como pressuposto que é competência exclusiva do município.

Adicionalmente, Almeida e Carneiro (2003), em uma pesquisa sobre liderança local, democracia e políticas públicas no Brasil, concluem que o governo local permanece claramente subordinado ao governo federal no combate aos problemas mais sérios do município. Os resultados revelam resistências potenciais à descentralização de atribuições e competências em várias áreas importantes para as suas comunidades entre as lideranças locais. A existência de uma tendência à valorização das funções do governo municipal não garante uma aceitação ampla de responsabilidades.

Para Abreu (1999, p. 32), um processo de descentralização que resguarde o federalismo implica alguns aspectos centrais:

[...] clara definição de competências entre os entes federados; redistribuição de encargos e responsabilidades, com a correspondente redistribuição de recursos e meios; descentralização do processo decisório, articulada com a participação de todos os níveis de governo na elaboração das normas gerais vigentes em toda a federação.

Kugelmas e Sola (1999) reforçam as ideias de Abreu (1999) de que uma das características do modelo federativo brasileiro é o grande número de competências conjuntas dos três níveis, sem uma definição clara das respectivas esferas, e esse é um dos problemas mais ponderáveis no equacionamento da descentralização das políticas sociais.

No que se refere à participação do município na garantia dos direitos sociais, especialmente da educação, Peixoto (1999) destaca que, nos anos 1990, a descentralização pela via da municipalização, induzida pelo governo federal, não representa uma possibilidade efetiva de democratização do ensino. Ao contrário, de modo 
geral, tem produzido um efeito desagregador sobre as redes municipais, afetando diretamente a sua expansão e a qualidade do ensino.

O autor ressalta, ainda, que o panorama municipal brasileiro é muito variado, com redes públicas de níveis elevados de ensino e escolas municipais unidocentes e multisseriadas no meio rural. Desse modo, a municipalização do ensino fundamental tem resultado, à exceção, talvez, do ocorrido nas capitais dos estados, em uma falsa solução. Em consequência, oferece-se às populações mais pobres um ensino de baixa qualidade.

Souza e Faria (2003) contribuem com a discussão ao ressaltarem que bons resultados do processo de ênfase à atuação municipal na educação são afetados pela própria conjuntura nacional em que ele se movimenta, em especial:

a) pela persistência e agravamento da crise econômica e da crise fiscal, assim como por um conjunto de macropolíticas federais que privilegiam a estabilidade monetária e o ajuste no qual se inclui uma reforma do Estado que reduz as suas ações e responsabilidades, incluindo a área social;

b) por conflitos de interesse entre os diversos níveis da federação e por padrões culturais e práticas políticas poderosas e arraigadas, adversas à transparência de recursos, poder e capacidade decisória implícitas em uma descentralização efetiva, bem como à democratização do aparato estatal;

c) pela enorme heterogeneidade territorial, econômica, social e política do país, com óbvios efeitos sobre a situação dos diversos estados e municípios e sobre a sua capacidade de atuação.

Como possibilidades para a inserção de modo distinto nesse cenário, Peixoto (1999) ressalta dois grandes desafios: buscar construir um sistema educacional no qual os três níveis governamentais atuem de forma integrada e compreender o município como parte integrante de um sistema mais amplo.

Souza e Faria (2003) salientam que a questão da efetividade do processo de descentralização vem, progressivamente, contemplando três aspectos considerados fundamentais pela quase totalidade dos analistas, os de natureza financeira, institucional e organizacional.

No tocante às questões de natureza financeira, Duarte (2003) argumenta que os municípios se diferenciam por sua capacidade de financiar a educação, o que, possivelmente, interfere na capacidade de implementação de proposta político-pedagógica. 
No campo institucional e organizacional, o processo de efetivação de sistemas autônomos na gestão da educação municipal implica elementos chave, como a implantação do regime de colaboração, e não mais a manutenção das relações hierárquicas entre as três esferas públicas de poder, ao se analisar limites e possibilidades dos municípios (BOAVENTURA, 1996 apud SOUZA; FARIA, 2003); a eliminação da mera transferência de atribuições somente no plano da administração, o que corrobora com o distanciamento entre as políticas executadas pelas outras esferas públicas em relação aos municípios que, muitas vezes, desconsideram as suas prioridades e especificidades locais, acabando, também, por se limitarem às ações de cunho administrativo e político-institucional (GONÇALVES, 1998; AZEVEDO, 2001 apud SOUZA; FARIA, 2003); a articulação para o enfrentamento das práticas excludentes, não garantindo a participação de todos os atores envolvidos com a instituição escolar na discussão desse processo de descentralização, com maiores responsabilidades aos municípios (ARELARO, 1999 apud SOUZA; FARIA, 2003).

Sarmento (2005) argumenta que a instituição do SME é questão estritamente relacionada ao pacto federativo no Brasil, que extrapola a política de municipalização acentuada nos anos 1990, firmando o município sua autonomia.

Para essa mesma autora, as questões referentes à organização dos sistemas de ensino, suas competências e responsabilidades não são assunto encerrado, e acrescenta à discussão da questão federativa outros aspectos considerados permanentes no que se refere à descentralização, como as disputas acerca da descentralização administrativa do sistema de educação, a ideia da autonomia e a distribuição de competências e responsabilidades entre os entes federativos (SARMENTO, 2005).

Ainda, segundo Sarmento (2005, p. 10), enfocando uma pesquisa realizada no estado de São Paulo, afirma que o processo de municipalização, forjado pela criação do Fundo de Manutenção e Desenvolvimento do Ensino Fundamental e Valorização do Magistério (Fundef) - a delimitação dos recursos e de sua aplicação coloca o município ante a opção de perder recursos ou assumir o ensino fundamental - foi percebido como “[...] imposição e encontrou os municípios despreparados para assumirem as novas responsabilidades. A municipalização induzida ofuscou a compreensão do significado de se criar um Sistema Municipal de Ensino como opção autônoma na condução da política educacional."

Segundo a autora, “[...] a pesquisa mostrou que um sistema único no âmbito municipal, com escolas responsáveis por todo o ensino fundamental, democraticamente administrado, é o ideal a ser alcançado.” E, ainda, “[...] a organização dos municípios e sua integração em entidades e associações desempenham um papel mais 
importante no trato da municipalização e criação de sistema próprio do que o fato de o estado ser rico ou pobre." (SARMENTO, 2005, p. 10-11).

Ao analisar o processo de desenvolvimento das políticas educacionais em três estados da Federação (Rio Grande do Sul, São Paulo e Minas Gerais), conclui Sarmento (2005, p. 11) que não apenas os países respondem às pressões externas pela descentralização e reorganização administrativa do mundo globalizado, conforme sua história e condições, mas também os estados em uma unidade federada. A organização dos sistemas municipais de ensino, como integrantes dos sistemas estadual e federal, envolve questões relacionadas ao poder local e significado ante o processo de globalização.

Para Saviani (1999), a definição clara da competência dos municípios para instituir os próprios sistemas de ensino flui da LDB, e não da CF. Portanto, não parece procedente a posição daqueles que entendem que a LDB, ao tornar opcional a organização dos sistemas municipais, teria enfraquecido a norma constitucional que não dispõe que os municípios poderão organizar seus sistemas, mas afirma que incumbir-se-ão de fazê-lo. Para o autor, a questão deve ser entendida como uma preocupação com as condições para a efetivação de sistemas no âmbito da educação municipal. E, nesse sentido, a LDB revela certa cautela ao prescrever, no parágrafo único do art. 11, que "[...] os municípios poderão optar, ainda, por se integrar ao sistema estadual de ensino ou compor com ele um sistema único de educação básica."

A LDB (BRASIL, 1996b) introduz a possibilidade de opção à luz de duas evidências: uma do ponto de vista formal, ao considerar a ambiguidade da CF (BRASIL, 1988) e outra do ponto de vista real, ao considerar as dificuldades técnicas e financeiras de muitos municípios para organizar em curto ou mesmo em médio prazo os seus sistemas. É de se notar que o reconhecimento dessa limitação está expresso, também, no Texto Constitucional, quando estabelece, no inciso VI do art. 30, a competência inequívoca dos municípios de manter programas de educação pré-escolar e de ensino fundamental, o que será feito com a cooperação técnica e financeira da União e do estado (SAVIANI, 1999).

Contudo, a despeito da cautela ao oferecer aos municípios a opção, ou não, pelo processo de institucionalização efetiva de SME, a LDB estabelece claramente a competência dos municípios para organizar os próprios sistemas.

Ao tratar dessas dúvidas e dificuldades, Sarmento (2005) declara que um pouco delas pode ser percebido com a análise das solicitações de esclarecimentos enviadas ao CNE e os pedidos de manifestação em questões relacionadas ao entendimento e ao alcance das determinações legais. Como exemplos dessas solicitações de 
esclarecimentos, a autora cita os Pareceres CNE/CEB n. 30/2000 (BRASIL, 2000) e n. 4/2001 (BRASIL, 2001a).

O Parecer n. 30/2000, motivado por solicitação da União Nacional dos Conselhos Municipais de Educação (UNCME) e relatado pelo conselheiro Cury (2000), refere-se aos sistemas de ensino e à organização da educação nacional.

Ao tratar da questão polêmica de os municípios serem ou não sistemas, com o advento da CF, Cury (2000) no Parecer CNE/CEB n.-30/2000, após ampla revisão legal, e apoiado em autores que estudam o tema, lembra que, ao contrário de um sistema hierárquico ou dualista, comumente centralizado, a CF estabelece um sistema de repartição de competências e atribuições legislativas entre os integrantes do sistema federativo, com limites expressos, reconhecendo a importância e a autonomia própria de cada um, não cabendo, portanto, incompatibilidades ou invasão de competências.

O Relator (CURY, 2000) considera dois momentos como estruturantes e capazes de perfazer as relações entre os sistemas de ensino do estado e os de seus municípios. O primeiro momento é o ponto de partida constitucional, quando os municípios, pela CF (BRASIL, 1988), são considerados sistemas de ensino, como uma consequência de seu caráter como pessoa jurídica e política de direito público interno com autonomia dentro de seu campo de atuação.

Cury (2000) explicita que até a promulgação da CF os municípios não eram titulares de sistemas de educação, restritos aos estados, ao Distrito Federal e à União, e poderiam existir por meio de uma delegação autorizativa dos estados. A CF instituiu os municípios como titulares de sistemas de ensino, ao permitir sua organização. Nas palavras do conselheiro,

[...] os sistemas de ensino da União, dos Estados, dos Municípios e do Distrito Federal, desde logo, passaram a ter existência constitucional, usufruindo de existência legal. Isto quer dizer que estes entes públicos integrados à Federação podem se organizar, respectivamente, como sistemas de educação. Sua organização e o seu modo de funcionamento ficariam sob a esfera da autonomia dos entes federativos, evitando antinomias entre órgãos normativos e executivos, obedecendo ao princípio da colaboração recíproca e das normas gerais da lei de diretrizes e bases da educação nacional (CURY, 2000, grifo nosso).

Contudo, segundo o Relator, a prática dessa titularidade dos municípios aguarda a devida regulamentação prevista pela LDB, a qual reconhece a existência do sistema federal e dos sistemas estaduais e municipais, o que, para o autor, é o segundo momento estruturante da organização dos SME. 
Cury (2000) argumenta que como a compreensão constitucional não ocorreu imediatamente para o conjunto dos municípios e como muitos deles não contavam com condições gerais e específicas " [...] para se instituírem e se organizarem como sistemas, na prática significou uma continuidade administrativa que até então vigia sob a Lei n.-4.024/61 e sob a Lei n. 5.692/71."

O Relator reconhece que as possibilidades de os municípios se integrarem ao SEE ou comporem com ele um sistema único de educação básica são, ainda, questões polêmicas. Ressalta que essas opções são possibilidades de colaboração entre os entes federados e que a autonomia, as atribuições e as competências de cada esfera devem ser respeitadas.

Considerando essas duas outras opções organizacionais dispostas na LDB (BRASIL, 1996b), Cury (2000) defende o processo de institucionalização efetiva de SMEds, como forma de garantir a autonomia municipal, também, no campo da educação. Em outros termos, a autonomia do município para a organização e a gestão de suas competências educacionais somente se efetivam se houver sistemas próprios de educação.

Conforme acentua, nem a CF, nem a LDB e nem outros pareceres do CNE projetam a constituição dos sistemas para um futuro indefinido, e a "[...] emergência dos municípios como sistemas de ensino, com base na Constituição, traz consigo a necessidade de que eles se efetivem como tais." (CURY, 2000, grifo nosso).

Os SMEs assentam-se na CF, mas demandam de efetivação, ou melhor, da institucionalização efetiva, como expressa o próprio texto: "O relator vota no sentido da institucionalização efetiva de sistemas municipais de ensino cujo funcionamento possa beneficiar os níveis de ensino próprios da sua autonomia e competência." (CURY, 2000, grifo nosso).

Considerando-se a pluralidade e assimetria dos municípios, o relator do $\mathrm{Pa}$ recer n. 30/2000 (BRASIL, 2000) reforça o regime de colaboração, "[...] para que os municípios possam exercer na plenitude sua autonomia por meio da instituição efetiva dos seus próprios sistemas de ensino." (CURY, 2000, grifo nosso).

Essa abertura no campo da interpretação do texto legal é, também, uma fonte de incertezas, em virtude da complexidade da teia de relações que se estabelecem. Por isso, mesmo com a definição das competências dos entes federados, o relator reclama a regulamentação do regime de colaboração, contido no parágrafo único do art. 23 da CF:

O Congresso, até a presente data, não regulamentou ainda este aspecto nuclear do pacto federativo. Trata-se de matéria da 
mais alta importância e significado para o conjunto das ações públicas e, em especial, para a manutenção e desenvolvimento do ensino. A feitura desta lei complementar possibilitaria o aprimoramento na sistematização das competências a fim de coordená-las de modo claro na forma, cooperativo na articulação e eficaz no desenvolvimento e bem-estar dos cidadãos brasileiros. (CURY, 2000, grifo nosso).

Em 2001, o CNE/CEB, ainda tendo como Relator o conselheiro Jamil Cury, emite outro Parecer, o den. 4 (BRASIL, 2001a), a propósito de consulta encaminhada pelo Conselho Municipal de Educação de São Paulo, reafirmando o entendimento de respeito à autonomia dos entes federados quanto à organização de seus órgãos normativos e executivos, resguardando-se os marcos legais.

Nessa complexidade, Duarte (2003) comenta que na gestão do governo federal, no período de 1995 a 2002, vários programas e projetos educacionais destinados aos municípios foram desenhados com a proposta da descentralização, constituindo, então, a ampliação da capacidade administrativa e institucional com a transferência voluntária de recursos, a possibilidade de elaboração e implementação de propostas pedagógicas pelos municípios para captação de recursos, a atribuição de definir os aspectos da gestão democrática pelos sistemas de ensino público. Contudo, essa proposta de descentralização veio associada a outros aspectos que podem impedir a verdadeira democratização na organização e na gestão da educação municipal, bem como o processo de institucionalização de sistemas municipais de educação, sendo a recentralização, a homogeneização e a ressignificação:

a) recentralização: o desenho de programas específicos, desenvolvidos pela União, promovem a recentralização da coordenação na formulação de políticas educativas para o país; e suas sistemáticas, como, por exemplo, convênios, subvinculações, financiamento, desconsideram as profundas diferenças nas condições financeiras, políticas e administrativas dos municípios; assim, ambos - desenho e sistemática contrapõem-se à autonomia na elaboração de planos de trabalho diferenciados, pois associam o repasse de recursos financeiros à realização de programas federais, independentemente das necessidades reais de cada localidade;

b) homogeneização: o estabelecimento de modelo único de financiamento para o país e da sistemática de transferência voluntária de recursos gera a presença dos mesmos programas nos municípios brasileiros; e a delimitação dos temas para a elaboração de planos de trabalho, forjam 
a reprodução e a conservação das propostas do governo central, apesar da diferença de fatores estruturais, como a capacidade fiscal e técnica, a dimensão da população, o número de matrículas, a formação dos trabalhadores da educação;

c) ressignificação: os municípios reproduzem as mesmas propostas da União, mas com nomes e modificações insignificantes, mantendo uma dinâmica de apropriação e ressignificação de programas e projetos desenvolvidos pelo governo federal como se fossem de origem local.

Nessa perspectiva, por um lado, o governo federal promove a ideia e capacidades de introduzir novas ações pelos municípios. Contudo, de outro, não estimula ou favorece efetivamente o crescimento da capacidade de tomada de decisão pelos territórios municipais acerca das propostas oferecidas nacionalmente, ficando os princípios da autonomia e do poder de auto-organização comprometidos.

Bordignon (apud GADOTTI, 2000, p. 163) contribui com a discussão acerca dessa complexidade, argumentando que a falta de articulação entre os sistemas de educação "[...] alimenta as desigualdades e incentiva o 'espírito patrimonialista' [...] complica as relações intergovernamentais [...] não permite um planejamento articulado e coerente dos serviços educacionais, resultando em atomização e/ou duplicação das ações.”

Andrade (2012, p. 399) toma como pressuposto que "[...] a opção do município pela criação de seu sistema constitui estratégia de ação coletiva em relação à definição e à implementação da sua Política Educacional"; ainda, que "[...] nessa forma de organização gestionária reside a esperança da superação do paradigma de gestão da educação centrado na figura do gestor, seja da Secretaria de Educação ou da escola." Contudo, ressalta que "[...] a própria estrutura de federativa adotada no País - em que se legitima a autonomia político-administrativa dos Estados e Municípios sem a clara posição quanto ao compartilhamento do poder decisório entre estes entes e a União - constitui principal entrave para a consolidação dessa forma de gestão.”

Ainda, segundo Andrade (2012, p. 399), “[...] estudos sobre a experiência da implantação dos sistemas de educação indicam que o rumo dado à apropriação das possibilidades de descentralização das políticas educacionais no âmbito do Poder Local ainda se confronta com obstáculos de caráter financeiro, político e cultural."

Da complexidade apresentada, faz-se pertinente defender a importância de estudos a respeito das experiências de gestão locais na forma de sistemas, ou de redes, com vistas à apreensão de outros limites e possibilidades para estas esferas se movimentarem no campo da educação. 


\section{SISTEMAS DE EDUCAÇÃO NO ÂMBITO DOS MUNICÍPIOS: CONCEPÇÕES CONSIDERANDO-SE O PROCESSO DE SUA INSTITUCIONALIZAÇÃO}

Apreendendo a discussão acerca de sistemas de educação no âmbito dos municípios, sobretudo se considerando o processo de sua institucionalização, no movimento histórico, Duarte (2003) destaca dissensos entre os setores considerados mais à esquerda, desde a discussão dos projetos de LDB no final dos anos 1980, até a proposta da descentralização da educação em sistemas municipais autônomos, além das ressignificações desse tema a partir dos anos 1990.

Em 1987, ressalta-se o posicionamento de restrição da autonomia dos sistemas municipais no âmbito da educação. Saviani (apud DUARTE, 2003), expressando, também, algumas das posições dos educadores brasileiros reunidos no Fórum em Defesa da Escola Pública (1987), no esboço de sua proposta de texto para a nova LDB, evita utilizar a expressão sistemas de ensino para resguardar o caráter de unidade, que entende ser a marca distintiva da noção de sistema. $\mathrm{O}$ conceito de autonomia dos sistemas municipais é conflitante com preocupações históricas voltadas para a superação das desigualdades sociais e regionais e com a constituição de um sistema unitário de educação no país. Assim, há uma defesa de maior centralização político-administrativa pela União e de restrição a sistemas municipais autônomos. O autor restringe a municipalização do ensino pela atribuição aos governos locais de responsabilidade pela oferta do ensino infantil e educação obrigatória (DUARTE, 2003).

Em relação à compreensão das possibilidades abertas quanto à compreensão dos sistemas de educação nos municípios, sua organização e funcionamento após a aprovação da Lei de Diretrizes e Bases da Educação Nacional (LDB) (BRASIL, 1996b), Saviani (1999) assinala que o termo sistema, em relação à educação, é empregado com acepções diversas, o que lhe confere um caráter, de certo modo, equivocado. O abuso da analogia resulta responsável por boa parte das confusões e imprecisões que cercam sua noção. A atitude que tem prevalecido entre os educadores em geral e, especialmente, entre os legisladores é a de evitar a questão relativa ao esclarecimento preciso do conceito de sistema, considerando-o algo constantemente referido, mas cujo sentido permanece sempre implícito, supostamente compreendido, mas jamais assumido explicitamente. Com isso, os legisladores, inadvertidamente, introduziram no texto, por analogia, o conceito de sistema municipal de ensino. 
Outra tese de Saviani (1999, p. 130) é que a questão de sistemas de educação no âmbito dos municípios “[...] dá margem a diferentes interpretações e alternativas, indo desde a possível negação de sua possibilidade até a sua não instalação por opção do município."

Bordignon (2004, p. 19) reafirma esse uso da expressão sistema de formas variadas no âmbito da educação, o que tem gerado distintas concepções e, como consequência, sua complexidade: “O termo sistema, importado da física pelas ciências sociais, tem sido usado, entre nós, com tal elasticidade que pode ser aplicado a quase tudo.”

Contribuindo para a construção do conceito de sistema, o referido autor explica que "[...] compreende um conjunto formando um todo autônomo de partes em relação funcional, orgânica e harmônica em vista de uma finalidade, que decorre dos valores prevalentes em determinada sociedade.” (BORDIGNON, 2004, p. 19).

$\mathrm{Na}$ mesma perspectiva, para Boaventura (1996), sistema, no âmbito da educação, é o conjunto de instituições de ensino e de normas organizadas tanto pela União, estados, Distrito Federal quanto pelos municípios. A ideia de sistema implica relacionamento entre partes, dinamicamente estabelecidas. Assim, o sistema municipal não poderá ser uma entidade desligada do contexto estadual.

Nas ideias de Cury (2000), a base dos sistemas municipais de ensino é sua existência constitucional - própria e autônoma - e consequente ao caráter do Município como pessoa jurídica e política de direito público interno, com autonomia dentro de seu campo de atuação. E essa base não exclui escolhas organizacionais que promovam articulações inventivas de municípios entre si e desses com o Estado.

Para Gadotti (2000, p. 164), em meio e no movimento das tendências universais e complementares nos últimos anos, “[...] a globalização da economia e dos meios de comunicação e o fortalecimento do poder local", e em um "contexto desalentador" no campo da educação, "[...] desponta uma instância educativa com uma força inédita: o poder local”, o que para ele "[...] é menos o fortalecimento das políticas locais e mais o das estruturas de poder que possibilitem aos cidadãos exercerem diretamente o seu poder." Assim, a despeito dessa complexidade, na concepção do referido autor, "Os sistemas educacionais municipais constituem-se hoje numa exigência da complexificação da sociedade, da explosão descentralizadora atual e do pluralismo político.”

Oliveira e Teixeira (2001) destacam a concepção e defendem a organização e a gestão da educação em nível municipal como uma possibilidade de democratização, como uma das perspectivas tratadas ao longo do tempo. Entretanto, não há, necessariamente, garantia de inclusão, de participação e de democratização das opor- 
tunidades de acesso e permanência na escola, considerando-se que pode significar a transferência de responsabilidades pela manutenção e desenvolvimento do ensino para municípios que não possuem as condições materiais e humanas para garantir ensino universal de qualidade.

Em 2009, Bordignon (2009), fundamentado pela concepção de sistema desenvolvido nas Ciências Sociais, propõe cinco princípios como fundantes para o modelo sistêmico em processo de consolidação no campo da educação, sendo a totalidade, a sinergia, a intecionaldiade, a autonomia, a organização e a normatização.

Com a discussão da institucionalização do Sistema Nacional de Educação e dos sistemas de ensino como estratégia de integração deste, compreende-se a necessidade do acirramento das discussões quanto à concepção de sistema municipal, sobretudo referente à sua abrangência e às suas possibilidades políticas, institucionais e organizacionais frente ao tamanho de suas atribuições.

\section{CONSIDERAÇÕES FINAIS}

De um modo ou de outro, reconhecidas as dificuldades, muitas das quais historicamente presentes na realidade dos municípios do Brasil, com a tese do fim das responsabilidades municipais com a educação infantil e com o ensino fundamental ou o seu contrário, essas esferas constituem-se importantes agentes da educação brasileira, e, interpretando a nova política educacional e sua respectiva legislação, executam-nas, e delas derivam novos enfoques político-educacionais, voltados aos seus respectivos campos de ação e prioridades locais. Investigar, portanto, a atuação dos municípios no campo da educação significa buscar um entendimento mais profundo acerca dos rumos da educação brasileira. Significa discutir condições e desafios, fragilidades e potencialidades que permeiam a existência dos municípios e sua atuação na educação. Significa discutir as condições internas e externas específicas aos municípios, como tradição histórica e cultural, organização política, aspectos ideológicos, geográficos, demográficos, financeiros, socioprofissionais, de planejamento e de gestão, e que perpassam esse processo.

Discussões convergindo para a identificação de condições favoráveis à opção dos municípios pela institucionalização dos sistemas próprios de educação, sempre em articulação com as políticas estaduais e nacionais.

Significa estimular a discussão acerca do Sistema Municipal de Educação para além da academia e dos gabinetes, inclusive abordando os elementos considerados necessários para a opção do município pelo processo de institucio- 
nalização efetiva de seu SME e visando a uma ação pública mais responsável e relevante socialmente.

Significa discutir como construir um Sistema Nacional de Educação respeitando as localidades e articulando-as.

Por fim, significa discutir acerca das raízes patrimonialistas e das relações patriarcais, personalistas e clientelistas, características presentes no Estado brasileiro, com vistas à superação dessa cultura política.

\section{REFERÊNCIAS}

ABREU, M. Descentralização e federalismo. Cadernos Aslegis, Brasília, v. 3, n. 7 , p. 30-35, jan./abr. 1999.

ALMEIDA, C. D. de; GUINDANI, J. F.; SÁ-SILVA, J. R. Pesquisa documental: pistas teóricas e metodológicas. Revista Brasileira de História \& Ciências Sociais, ano 1, n. 1, jul. 2009.

ALMEIDA, M. H. T. de; CARNEIRO, L. P. Liderança local, democracia e políticas públicas no Brasil. Opinião Pública, Campinas, v. 9, n. 1, p. 124-147, maio 2003.

ANDRADE, E. F. de. Sistemas municipais de educação: impactos na gestão educacional no âmbito do poder local. Campinas: Mercado das Letras, 2012.

BOAVENTURA, E. M. (Org.). Políticas municipais de educação. Salvador: Edufba; Fundação Clemente Mariani, 1996.

BORDIGNON, G. Gestão da Educação no Município: sistema, conselho e plano. São Paulo: Instituto Paulo Freire, 2009.

BORDIGNON, G. Conselhos na gestão da educação. In: BRASIL. Programa Nacional de Fortalecimento dos Conselhos Escolares: conselhos escolares: uma estratégia de gestão democrática da educação pública. Brasília: Ministério da Educação/Secretaria de Educação Básica (MEC/SEB), 2004.

BRASIL. Constituição. República Federativa do Brasil de 1988. Brasília, DF: Senado Federal, 1988.

BRASIL. Emenda Constitucional n. 14, de 12 de setembro de 1996. Modifica os artigos 34, 208, 211 e 212 da Constituição Federal. Diário Oficial da União, Brasília, DF, 12 set. 1996 a. 
BRASIL. Emenda Constitucional n. 59, de 11 de novembro de 2009. Reduz o percentual da DRU incidente sobre os recursos destinados à manutenção e desenvolvimento do ensino, amplia a obrigatoriedade do ensino e de programas suplementares para a educação básica. Diário Oficial da União, Brasília, DF, 11 nov. 2009.

BRASIL. Lei n. 9.394, de 20 de dezembro de 1996. Estabelece a Lei de Diretrizes e Bases da Educação Nacional. Diário Oficial da União, Brasília, DF, 20 dez. 1996b.

BRASIL. Lei n. 9.424, de 24 de dezembro de 1996. Dispõe sobre o Fundo de Manutenção do Ensino Fundamental e de Valorização do Magistério (Fundef). Diário Oficial da União, Brasília, DF, 24 dez. 1996c.

BRASIL. Parecer n. 4, de 30 de janeiro de 2001. Consulta sobre o entendimento e o alcance das expressões “Órgão responsável pela Educação e Órgãos responsáveis pelos Sistemas de Ensino”. Diário Oficial da União, Brasília, DF, 30 jan. 2001a.

BRASIL. Parecer n. 30, de 12 de setembro de 2000. Solicita pronunciamento, tendo em vista o Parecer CEB 04/2000. Diário Oficial da União, Brasília, DF, 12 set. 2000.

BRASIL. Parecer n. 34, de 05 de novembro de 2001. Consulta sobre autorização de funcionamento e supervisão de instituições privadas de Educação Infantil. Diário Oficial da União, Brasília, DF, 05 nov. 2001 b.

CELLARD, A. A análise documental. In: POUPART, J. et al. A pesquisa qualitativa: enfoques epistemológicos e metodológicos. Petrópolis: Vozes, 2008.

CURY, C. R. J. (Relator). BRASIL. Conselho Nacional de Educação (CNE). Câmara de Educação Básica (CEB). Parecer n. 4, de 30 de janeiro de 2001. Brasília, 2001.

CURY, C. R. J. (Relator). BRASIL. Conselho Nacional de Educação (CNE). Câmara de educação Básica (REB). Parecer n. 30, de 12 de setembro de 2000. Brasília, 2000 .

DUARTE, M. R. T. Sistemas públicos de educação básica e relações intergovernamentais: a ação da União e a autonomia dos sistemas locais de ensino. 2003. Tese (Doutorado)-Universidade Federal Fluminense/Faculdade de Educação (UFF/FE), Niterói.

FONSECA, J. P. da. Poder local e municipalização: em busca da utopia - um estudo no município de Jacuí (MG). 1995. Tese (Livre-Docência)-Universidade de São Paulo, São Paulo, 1995.

GADOTTI, M. Perspectivas atuais da educação. Porto Alegre: Artes Médicas Sul, 2000. 
KUGELMAS, E.; SOLA, L. Recentralização/descentralização: dinâmica do regime federativo no Brasil dos anos 90. Tempo Social, São Paulo, v. 11, n. 2, p. 63-81, out. 1999.

LIMA, T. C. S. de; MIOTO, R. C. T. Procedimentos metodológicos na construção do conhecimento científico: a pesquisa bibliográfica. Rev. Katál., Florianópolis, v. 10, p. 37-45, 2007.

OLIVEIRA, C. de; TEIXEIRA, L. H. G. Municipalização e gestão municipal. In: WITTMANN, Lauro Carlos; GRACINDO, Regina Vinhaes (Coord.). O estado da arte em política e gestão da educação no Brasil: 1991 a 1997. Brasília, DF: Anpae; Campinas: Autores Associados, 2001.

PEIXOTO, M. do C. L. Descentralização da educação no Brasil: uma abordagem preliminar. In: OLIVEIRA, Dalila Andrade; DUARTE, Marisa Ribeiro Teixeira (Org.). Política e trabalho na escola: administração dos sistemas públicos de educação básica. Belo Horizonte: Autêntica, 1999.

SANDER, B. Sistemas e anti-sistemas na educação brasileira. Revista Brasileira de Estudos Pedagógicos, Brasília, DF, v. 74, n. 177, p. 335-370, maio/ago. 1993.

SARMENTO, D. C. Autonomia municipal: sistemas municipais de ensino. Revista Educação em Foco, Juiz de Fora, v. 9, n. 1/2, p. 149-168, mar./ago. 2004, set./fev. 2005.

SAVIANI, D. Sistemas de ensino e planos de educação: o âmbito dos municípios. Educação \& Sociedade. Campinas, ano 20, n. 69, p. 119-136, dez. 1999.

SAVIANI, D. Educação brasileira: estrutura e sistema. 7. ed. Campinas: Autores Associados, 1996.

SOUZA, C.; CARVALHO, I. M. M. de. Reforma do Estado, descentralização e desigualdades. Lua Nova, São Paulo, n. 48, p. 187-212, 1999.

SOUZA, D. B. de; FARIA, L. C. M. de (Org.). Desafios da educação municipal. Rio de Janeiro: DP\&A, 2003. 